\title{
An integrated computational-experimental approach reveals Yersinia pestis genes essential across a narrow or a broad range of environmental conditions
}

\author{
Nicola J. Senior', Kalesh Sasidharan², Richard J. Saint ${ }^{3}$, Andrew E. Scott ${ }^{3}$, Mitali Sarkar-Tyson ${ }^{3,4}$, Philip M. Ireland ${ }^{3}$, \\ Helen L Bullifent ${ }^{3}$, Z. Rong Yang ${ }^{1}$, Karen Moore ${ }^{1}$, Petra C. F. Oyston ${ }^{3}$, Timothy P. Atkins ${ }^{1,3}$, Helen S. Atkins ${ }^{1,3}$, \\ Orkun S. Soyer ${ }^{2}$ and Richard W. Titball ${ }^{1 *}$ (D)
}

\begin{abstract}
Background: The World Health Organization has categorized plague as a re-emerging disease and the potential for Yersinia pestis to also be used as a bioweapon makes the identification of new drug targets against this pathogen a priority. Environmental temperature is a key signal which regulates virulence of the bacterium. The bacterium normally grows outside the human host at $28{ }^{\circ} \mathrm{C}$. Therefore, understanding the mechanisms that the bacterium used to adapt to a mammalian host at $37^{\circ} \mathrm{C}$ is central to the development of vaccines or drugs for the prevention or treatment of human disease.

Results: Using a library of over 1 million $Y$. pestis CO92 random mutants and transposon-directed insertion site sequencing, we identified 530 essential genes when the bacteria were cultured at $28^{\circ} \mathrm{C}$. When the library of mutants was subsequently cultured at $37^{\circ} \mathrm{C}$ we identified 19 genes that were essential at $37^{\circ} \mathrm{C}$ but not at $28^{\circ} \mathrm{C}$, including genes which encode proteins that play a role in enabling functioning of the type III secretion and in DNA replication and maintenance. Using genome-scale metabolic network reconstruction we showed that growth conditions profoundly influence the physiology of the bacterium, and by combining computational and experimental approaches we were able to identify 54 genes that are essential under a broad range of conditions.

Conclusions: Using an integrated computational-experimental approach we identify genes which are required for growth at $37^{\circ} \mathrm{C}$ and under a broad range of environments may be the best targets for the development of new interventions to prevent or treat plague in humans.
\end{abstract}

Keywords: Yersinia pestis, Plague, TRADIS, Transposon, Essential genes, Metabolic model

\section{Background}

Yersinia pestis is a Gram-negative bacterium and the causative agent of plague [1]. Various schemes have been proposed to sub-type $Y$. pestis, and the most frequently used places strains into one of three biovars (Antiqua, Mediaevalis or Orientalis) on the basis of the differential ability of isolates to ferment glycerol and reduce nitrate [2]. Of these, biovar

\footnotetext{
* Correspondence: r.w.titball@exeter.ac.uk

${ }^{1}$ College of Life and Environmental Sciences, University of Exeter, Exeter EX4 $4 \mathrm{SB}, \mathrm{UK}$

Full list of author information is available at the end of the article
}

Orientalis strains are associated with the most recent outbreaks of disease. Plague remains a threat in many parts of the world, particularly Africa [1], and the World Health Organization has categorized plague as a re-emerging disease. There is currently no licensed vaccine against plague in the West, while a multidrug resistant strain has emerged in Madagascar [3]. These findings and the potential of $Y$. pestis to be used as a bioweapon [4] make the findings of this study highly relevant towards identifying new drug targets against this pathogen. 
$Y$. pestis can infect a wide range of mammalian hosts $[1,5]$. Although it can be transmitted in aerosols to generate primary pneumonic plague or via ingestion, most natural cases arise following the bite of an infected flea [1]. Plague can survive and replicate in the digestive tract of the flea and as the infected flea attempts to feed, bacteria are regurgitated into the bite site and the mammalian host is infected. Therefore, the bacterium can survive in two distinct environments and a key environmental stimulus affecting gene expression in these niches is temperature. In the flea, typically at $22-30{ }^{\circ} \mathrm{C}$ genes such as those responsible for extracellular matrix and biofilm formation and for the murine toxin play key roles. [6]. In the mammalian host, virulence factors are upregulated at $37{ }^{\circ} \mathrm{C}$, including the F1 antigen capsule and the plasmid pCD1-encoded type III secretion system [7].

Next-generation sequencing and transposon mutagenesis are powerful technologies for the genomewide identification of gene functions in bacterial pathogens [8]. When combined, they allow the precise mapping of the DNA sequence spanning the junction between the transposon and the recipient DNA [8]. Consequently, millions of mutants can be simultaneously and individually monitored for their frequency within a population. By exposing the population to a specific stress, mutants that are disadvantaged can be revealed [9]. Consequently it has been possible to identify genes that are necessary for growth [8]. These genes are "essential" because their inactivation results in a fitness disadvantage, within an otherwise wildtype population. Essential genes or their products can be targets for novel therapeutics [10]. Depending on the transposon used and the sequencing methodology employed, the technology has been called INSeq (insertion sequencing), Tn-seq (transposon sequencing), TraDIS (transposon-directed insertion site sequencing) or HITS (high-throughput insertion tracking by deep sequencing) and these different methods have recently been reviewed [11].

In conjunction with this powerful experimental approach, it is possible to apply computational tools to predict essential genes under different conditions and for a wide range of pathogens. This integrative approach can provide mechanistic explanations for experimentally identified essential genes, such as identifying conditions which modify gene essentiality. To this end several studies explored the possibility of identifying essential genes from genome-scale, stoichiometric metabolic networks through the application of flux balance analysis [12, 13]. This approach allows prediction of biomass production under a defined media composition and subsequent interrogation of the effects of in silico deletion of genes on growth, i.e. gene essentiality. While such computational prediction of gene essentiality is attractive, to date, there are not many systematic studies that perform computational predictions under different media conditions and compare these predictions on gene essentiality with corresponding experimental studies in the same organism.

Previously, we developed a novel algorithm for the experimental identification of essential genes in $Y$. pestis CO92 grown at $28{ }^{\circ} \mathrm{C}$ and identified 548 essential genes [14]. Here, we apply an integrated computationalexperimental approach to investigate gene essentiality in $Y$. pestis grown at $28{ }^{\circ} \mathrm{C}$ and $37^{\circ} \mathrm{C}$. The application of experimental mutagenesis and metabolic modelling in this study highlights the presence of environmental conditionspecific, as well as "core" essential genes. The latter group of genes are predicted to be required for growth under a broad range of environments and represent preferential targets for the development of new interventions to control disease.

\section{Methods \\ Generation of mutants}

$Y$. pestis strain CO92 was originally isolated from a fatal human case of primary pneumonic plague contracted from an infected cat and has been genome sequenced [15]. The bacteria were cultured in blood agar base (BAB) broth or BAB agar supplemented with hemin $(0.025 \% \mathrm{w} / \mathrm{v})$ at $28{ }^{\circ} \mathrm{C}$. When required, media was supplemented with kanamycin $\left(25 \mu \mathrm{g} \mathrm{ml}^{-1}\right)$, trimethoprim $\left(100 \mu \mathrm{g} \mathrm{ml}^{-1}\right)$, chloramphenicol $\left(25 \mu \mathrm{g} \mathrm{ml}^{-1}\right)$. L-rhamnose $(0.02 \%)$ or Lglucose $(0.1 \%)$. A library of over 1 million mutants was constructed in $Y$. pestis $\mathrm{CO} 92$ by random mutagenesis using the EZ-Tn5 < kan-2 > Tnp transposome kit (Epicentre) according to the manufacturer's instructions. Y. pestis was cultured in broth at $28{ }^{\circ} \mathrm{C}$ and was made electro-competent by sequential washes in $10 \%$ glycerol. Parameters defined previously for the electroporation of $Y$. pestis to high efficiency were applied [16]. After electroporation, cells recovered for $2 \mathrm{~h}$ in $\mathrm{BAB}$ broth prior to plating. Mutants were washed from the plates and pooled into batches of approximately $2 \times 10^{5}$ colonies before combining to create the final transposon library.

\section{Sequencing of mutants}

Transposon libraries were cultured in $\mathrm{BAB}$ broth at $28{ }^{\circ} \mathrm{C}$ or $37{ }^{\circ} \mathrm{C}$ overnight and genomic DNA extracted using the Gentra Puregene kit (Qiagen). The gDNA was fragmented to $<500$ base pairs (bp) using $2 \times 15$ min cycles at $4{ }^{\circ} \mathrm{C}$ in a BioRuptor sonicator (medium intensity, 30s on/90s off). A NEBNext DNA library preparation for Illumina kit (NEB) was used 
according to the manufacturer's instructions, to end repair, A-tail and ligate adapters to the fragments. The adapters used were Ind_Ad-T and Ind_Ad-B (Additional file 1: Table S1), which were annealed prior to use. Parallel polymerase chain reaction (PCR) samples were set up with $10 \mu \mathrm{l}$ JumpStart $10 \times$ buffer, $6 \mu \mathrm{l} \mathrm{MgCl}_{2}, 2 \mu \mathrm{l} 10 \mathrm{mM}$ nucleoside triphosphates (dNTPs), $0.6 \mu \mathrm{l} 100 \mu \mathrm{M}$ PE_PCR_V3.3 primer, $0.6 \mu \mathrm{l}$ $100 \mu \mathrm{M}$ Yp_EzTn_PCR primer, $1 \mu \mathrm{l}$ JumpStart Taq DNA polymerase and $28.8 \mu \mathrm{l}$ nuclease-free water per reaction. Primer sequences are listed in Additional file 2: Table S2. The reactions were amplified at $94{ }^{\circ} \mathrm{C}$ for $2 \mathrm{~min}$, $\left(94{ }^{\circ} \mathrm{C}\right.$ for $30 \mathrm{~s}, 60^{\circ} \mathrm{C}$ for $20 \mathrm{~s}, 72^{\circ} \mathrm{C}$ for $30 \mathrm{~s}$ ) for 22 cycles, $72{ }^{\circ} \mathrm{C}$ for $10 \mathrm{~min}$, then held at $12{ }^{\circ} \mathrm{C}$. PCR products were pooled and ethanol precipitated before being size selected on a $2 \%(w / v)$ agarose tris-borate-EDTA (TBE) gel. Agarose blocks corresponding to $350-500$ bp were excised, and the DNA extracted using a Qiagen MinElute Gel Extraction kit as per the manufacturer's instructions. The DNA was quantified by qPCR and on an Agilent BioAnalyzer before being submitted for sequencing as $100 \mathrm{bp}$ single end reads on an Illumina HiSeq 2500 standard model. In total, there were 57.2 million raw sequencing reads. 45.8 million (80.1\%) were transposon sequences. Nine million (19.7\%) transposon sequences were mapped to the genome (AL59084). This sequence data has been submitted to the NCBI Sequence Read Archive (SRA) database under accession numbers GSE100226, GSM2674959, GSM2674960, GSM2674961, GSM2674962, GSM2674963, GSM2674964 and GSM2674965.

\section{Data processing of transposon insertion data}

Data was processed using an algorithm that we have previously devised [14] and which predicts gene essentiality based on the number and location of transposon insertions within each gene. Genes that lacked any transposon insertions were termed Type I essential genes. The remaining genes were then subjected to noise trimming using a tight cluster approach, and those classed as essential by this were termed Type II essential genes. Finally, genes had their individual mutation features calculated and our algorithm used to identify Type III essential genes [14].

\section{Metabolic model for $Y$. pestis $\mathrm{CO} 22$}

The previously reported metabolic model for $Y$. pestis CO92 [17] was downloaded and used without any alterations, except for the setting of exchange reaction bounds for simulation of different environments (see below).

\section{Functional gene analysis}

The latest Cluster of Orthologous Groups (COGs) information was downloaded from ftp://ftp.ncbi.nih.gov/pub/
COG/COG2014/data on June 27 2015. The functional category of each gene in the $Y$. pestis CO92 model was then identified from the COGs tables. Other relevant information, such as gene ID and GI number were obtained using NCBI E-utilities (http://eutils.ncbi.nlm.nih.gov).

\section{Metabolic gene essentiality analysis under different environments}

In this analysis, the metabolic model is simulated under a specific environment, which is set by constraining the exchange fluxes to specific values (exchange reactions manage the import and export of metabolites between the cell and the environment/ medium). Within the specified environment, flux through each reaction in the model was disabled one at a time and the resulting model (corresponding to a single gene knockout mutant) was optimised for biomass objective function (BOF) as before [18]. If the altered model did not result in any feasible optima (if flux through the BOF was less than $1 \%$ of the original growth rate; i.e. $<0.0028$ ), then the gene corresponding to the disabled reaction was considered as essential under that environment.

The BCS media is simulated in the model using the 21 exchange reactions involving metabolites found in that media, however, the original model has a total of 281 exchange reactions. That means, if we were to try all combinations of the exchange reactions to generate possible environments, there would be $2^{281}$ different environments (media compositions). This number is too large to analyse in a tractable manner under reasonable computational resources and time. Therefore, we have used the following two approaches to sample this possible environment space to obtain a set of feasible number of diverse media compositions: (a) generate all the combinations of the 17 out of 21 exchange reactions used in the BCS medium (in this approach four exchange reactions were always supplied because they are found to be essential for growth in BCS medium; L-methionine, $\mathrm{O}_{2}, \mathrm{~L}-$ phenylalanine and phosphate), (b) generate over 2 million random combinations of all the exchange reactions ( $\mathrm{L}$-phenylalanine was supplied in all random media as it is found to be an essential metabolite for growth in all the media).

By setting a theoretical, "maximal environment" that contained all substrates that the model can take up (i.e. the lower-bounds of all exchange reactions are set to -1000), we identified a set of "super" essential genes. The BOF feasibility cut-off used in this analysis was $1 \%$ of the growth rate under the maximal environment; i.e. $<1.2244$. 


\section{Results and discussion}

\section{Experimental identification of $Y$. pestis $\mathrm{CO} 22$ essential} genes

We previously reported the construction of a library of over 1 million mutants in $Y$. pestis CO92 by random mutagenesis using the EZ-Tn $5<$ kan- $2>$ Tnp transposon [14]. Genes that were essential for growth of $Y$. pestis at $28{ }^{\circ} \mathrm{C}$ were identified using TraDIS. We processed data from three biological replicates, and identified 530 genes which were essential when the bacteria were cultured at $28{ }^{\circ} \mathrm{C}$. In this study we grew the library at $37{ }^{\circ} \mathrm{C}$ and identified genes essential at this temperature.

In order to study the functions of the experimentally identified essential genes we used COG data information on $Y$. pestis $\mathrm{CO} 92$ proteins. The most frequently represented groups, at $28{ }^{\circ} \mathrm{C}$ or $37{ }^{\circ} \mathrm{C}$, were those including "translation, ribosomal structure and biogenesis" and "cell wall or membrane or envelope biogenesis" proteins. In the combined $28{ }^{\circ} \mathrm{C}$ and $37{ }^{\circ} \mathrm{C}$ datasets these groups were $18.7 \%$ and $10.5 \%$ respectively of the total (Fig. 1). However both the $28{ }^{\circ} \mathrm{C}$ and $37{ }^{\circ} \mathrm{C}$ essential gene lists included "unidentified" genes (Fig. 1).

The "replication, recombination and repair" (10.5\%) cluster was prominent among the genes that were essential only at $28{ }^{\circ} \mathrm{C}$, whereas "Inorganic ion transport and metabolism" (16.7\%), "translation, ribosomal structure and biogenesis" (12.5\%) and "nucleotide transport and metabolism" (12.5\%) clusters were dominant among the genes that are essential only at $37^{\circ} \mathrm{C}$.

\section{Genes essential at $37^{\circ} \mathrm{C}$, but not at $28^{\circ} \mathrm{C}$, may play roles in virulence}

We identified 19 genes which were essential at $37{ }^{\circ} \mathrm{C}$ but not at $28{ }^{\circ} \mathrm{C}$ (Table 1). Several of these are likely to play a role in enabling the type III system, which is expressed at $37{ }^{\circ} \mathrm{C}$ but not at $28{ }^{\circ} \mathrm{C}$ [19]. The type III system is a major virulence determinant in $Y$. pestis and its expression can result in the suppression of bacterial growth [19]. Previously a $p s p C$ mutant of Yersinia enterocolitica has been shown to be attenuated in mice, and defective in growth in vitro when the type III system was induced (16). This is believed to reflect the ability of the Psp response to protect the cell envelope after induction of the type III system (17). Furthermore a $p s p B$ mutant showed sensitivity to overexpression of the YsaC secretin component of the type III system. It is believed that this is because misfolded secretin is lethal in the absence of the Psp response [20]. The $\operatorname{trk} A$ gene encodes a peripheral membrane protein and is a key component of the Trk low affinity $\mathrm{K}+$ transport

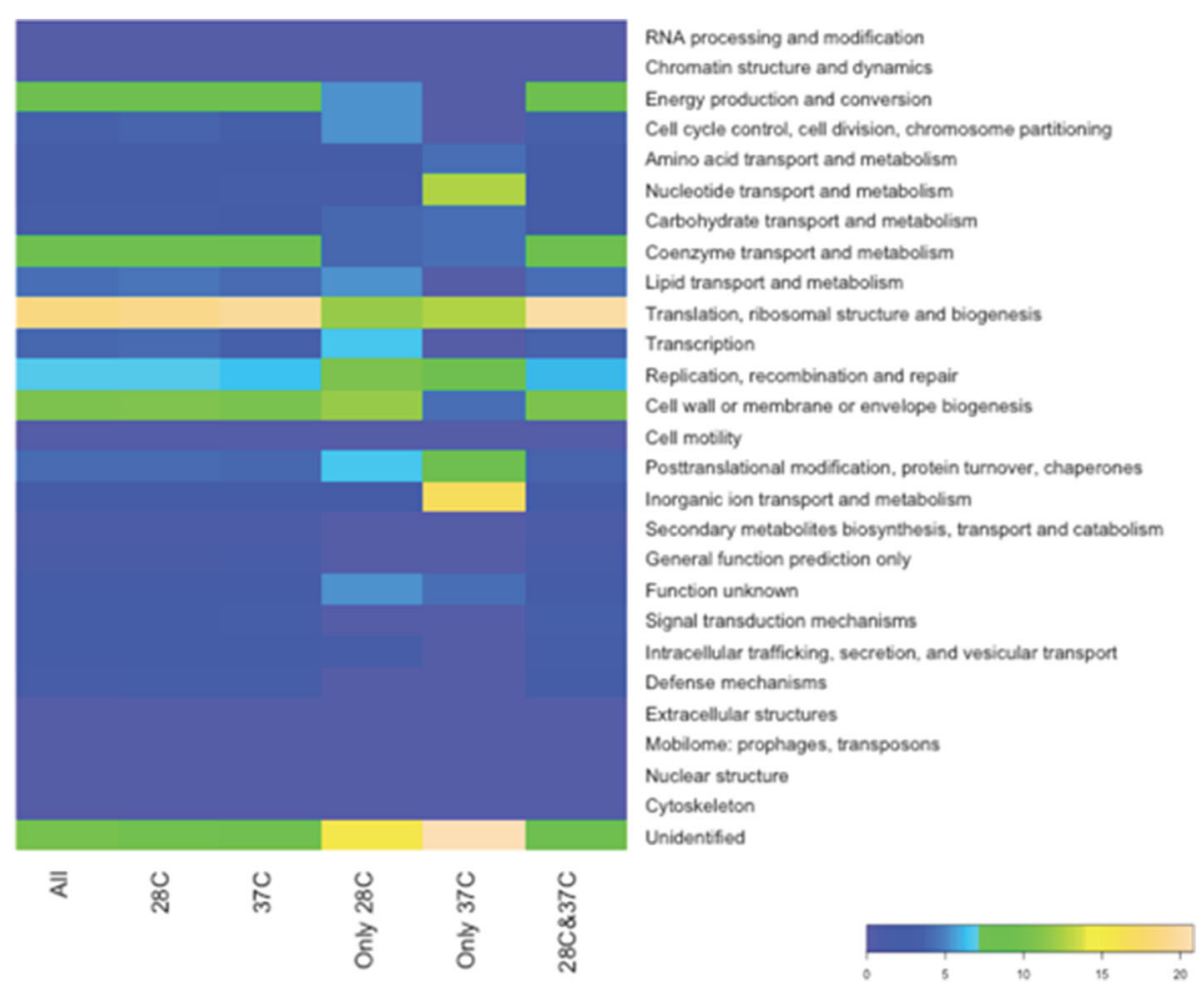

Fig. 1 Analysis of the experimentally identified Y. pestis CO92 essential genes. A heat-map showing the percentage of COGs in different groups of essential genes (x axis); "All", all essential genes; " $28 C^{\prime \prime}$, genes that are essential at $28^{\circ} \mathrm{C}$; " $37 \mathrm{C}^{\prime \prime}$, genes that are essential at $37^{\circ} \mathrm{C}$; "Only $28 \mathrm{C}^{\prime}$, genes that are essential only at $28^{\circ} \mathrm{C}$; "Only $37 \mathrm{C}^{\prime}$, genes that are essential only at $37^{\circ} \mathrm{C} ;$ " $28 \mathrm{C}$ and $37 \mathrm{C}$ ", essential genes common at both temperatures 
Table 1 Genes experimentally identified to be essential at $37^{\circ} \mathrm{C}$ but not $28^{\circ} \mathrm{C}$

\begin{tabular}{|c|c|c|}
\hline Gene number & $\begin{array}{l}\text { Gene } \\
\text { name }\end{array}$ & Gene product \\
\hline YPO0239 & $\operatorname{trk} A$ & $\begin{array}{l}\text { potassium transporter peripheral membrane } \\
\text { component }\end{array}$ \\
\hline YPO0331 & уро0331 & hypothetical protein \\
\hline YPO0492 & $k s g A$ & dimethyladenosine transferase \\
\hline YPO0892 & xerD & site-specific tyrosine recombinase \\
\hline YPO1020 & $\operatorname{rec} B$ & exonuclease $v$ subunit beta \\
\hline YPO1101 & $s m p B$ & SsrA-binding protein \\
\hline YPO1102 & уро1102 & hypothetical protein \\
\hline YPO1213 & $n r d B$ & $\begin{array}{l}\text { ribonucleotide-diphosphate reductase } \\
\text { subunit beta }\end{array}$ \\
\hline YPO1391 & $\mathrm{cmk}$ & cytidylate kinase \\
\hline YPO2159 & уро2159 & hypothetical protein \\
\hline YPO2327 & уро2327 & lipoprotein \\
\hline YPO2350 & $p s p B$ & phage shock protein $B$ \\
\hline YPO2883 & $n d k$ & nucleoside diphosphate kinase \\
\hline YPO2894 & isc $A$ & iron-sulfur cluster assembly protein \\
\hline YPO2907 & glyA & serine hydroxymethyltransferase \\
\hline YPO3173 & thii & thiamine biosynthesis protein Thil \\
\hline YPO3696 & trec & trehalose-6-phosphate hydrolase \\
\hline YPO3847 & cyar & frataxin-like protein \\
\hline YPO3864 & $n f r C / w e c B$ & UDP-N-acetylglucosamine 2-epimerase \\
\hline
\end{tabular}

system in Gram negative bacteria [21]. In S. enterica, reduced intracellular growth and virulence has been linked to the decreased secretion of SPI1 type III system effectors by a trkA mutant [22]. TrkA has also been implicated in sensitivity to overexpression of the YsaC secretin in $Y$. enterocolitica [20], mirroring the phenotype of $p s p B$ mutants.

The $\operatorname{smp} B$ gene product might also play a role in the Yersinia type III system. SmpB interacts with transfermessenger RNA (tmRNA) and along with SsrA they mediate ribosome recycling in the event of stalling on mRNA during translation [23]. In Yersinia pseudotuberculosis and $Y$. pestis smpB-ssrA mutants show reduced secretion of type III effectors at $37{ }^{\circ} \mathrm{C}$ and a $Y$. pestis smpB-ssrA mutant is markedly attenuated in mice [24].

Another group of genes that were essential at $37{ }^{\circ} \mathrm{C}$ but not at $28{ }^{\circ} \mathrm{C}(n r d B, n d k, c m k, x e r D$ and $\operatorname{recB})$ encode proteins associated with DNA replication and maintenance. NrdB is the $\beta$-subunit of ribonucleotidediphosphate reductase, and plays a key role in the first step of synthesis of DNA precursors. In Escherichia coli, an $n r d B$ mutant is temperature sensitive, which is believed to reflect the increased deoxyribonucleotide demand associated with increased growth rates at higher temperatures [25]. The $n d k$ gene encodes a nucleoside diphosphate kinase, which plays a key role in the synthesis of nucleoside triphosphates such as GTP. Consequently, it is not surprising that the gene plays a role in virulence of pathogens such as Mycobacterium tuberculosis [26] and Pseudomonas aeruginosa [27] and is upregulated during Salmonella enterica infections [28]. In addition studies with $M$. tuberculosis show that $n d k$ plays a role in phagosome maturation, promoting growth of the bacteria [26]. Thus in this case it appears to have an effector-like function. In some species, such as $S$. enterica, mutation of $n d k$ imparts a cold sensitive phenotype [29]. Cytidine monophosphate kinase (Cmk) plays a crucial role in the recycling of nucleoside precursors to fuel DNA synthesis, acting alongside NdrB and a cmk mutant of $Y$. pseudotuberculosis is attenuated in mice [30]. Cmk mutants of other pathogens have been shown to have growth defects, and in some cases these are temperature dependent $[31,32]$. The $x e r D$ gene is a component of the $x e r C D$ complex, which plays a role in the segregation of replicated chromosomal and plasmid DNA. This gene was essential for in vitro growth of $S$. aureus [33] and a Brucella abortus xerD mutant was attenuated in mice [34]. We also identified $\operatorname{rec} B$ as essential at $37{ }^{\circ} \mathrm{C}$ but not $28{ }^{\circ} \mathrm{C}$. RecB is a helicase and part of the RecBCD complex, which plays a key role in the repair of double stranded DNA breaks [35]. Although there is also redundancy in this pathway [35], the loss of RecBCD or RecB decreases the ability of bacteria to withstand stresses including elevated temperatures. Thus it is not surprising that $\operatorname{rec} B$ mutants of pathogens such as E. coli, S. enterica [35] and Helicobacter pylori [36] are attenuated. Overall, it seems that these DNA replication and maintenance proteins are more essential at higher temperatures.

The remaining genes are predicted to play roles in stress responses (cya $Y$ and iscA) [37, 38], the modification of adenosines in the small ribosome sub-unit $(k s g A)$ [39], the generation of thiamine pyrophosphate, an essential co-factor for many enzymes (thil) [40], carbon metabolism ( $g l y A$ and treC) and the biosynthesis of the enterobacterial common antigen $(n f r C / w e c B)$. Some of these genes have previously been shown to play a role in the virulence of $Y$. pestis (wecB [41]), Y. pseudotuberculosis (ksgA [42]) or other pathogens (cyaY [43], glyA [44-46], treC [47]).

The functions of four of these genes identified as essential at $37{ }^{\circ} \mathrm{C}$ but not at $28{ }^{\circ} \mathrm{C}$ (YPO0331, YPO1102, YPO2159 and YPO2327) could not be predicted on the basis of motif or homology matches, although YPO2327 is predicted to be a lipoprotein and is therefore likely to be surface located. These proteins should be a focus of future investigations to establish their possible roles in virulence. There was little overlap of our list of genes essential at $37{ }^{\circ} \mathrm{C}$ with previously reported data on genes 
upregulated at $37{ }^{\circ} \mathrm{C}$ in broth $[48,49]$ or in serum [50] or with the reported data on proteins with increased abundance in bacteria grown at $37{ }^{\circ} \mathrm{C}$ [51]. These findings highlight the importance of using several methodologies to obtain a robust picture of the molecular changes that occur in bacteria exposed to different conditions.

Experimentally identified essential genes in $Y$. pestis CO92 overlap with, but differ from, those identified in $Y$. pestis KIM 1001

Palace et al. [52] previously reported the use of Tn-seq to probe the genome of $Y$. pestis KIM 1001 (biovar Mediaevalis) for elements contributing to fitness. Applying a Hidden Markov Method (HMM), Palace et al. classified genes as essential, growth-advantaged, growthdisadvantaged or non-essential at $37{ }^{\circ} \mathrm{C}$. They identified 624 essential genes, including 19 located on the plasmids. We compared this list with the essential genes we identified in Y. pestis CO92 at $28{ }^{\circ} \mathrm{C}$ or $37^{\circ} \mathrm{C}$ and found that 433 and 397 genes respectively were common to both studies. Of the 397 genes identified in both studies at $37{ }^{\circ} \mathrm{C}, 97 \%$ had homologues already identified in the Database of Essential Genes (DEG) (Additional file 3: Table S3). The differences in the two experimental lists of essential genes might reflect differences in the biology of these two strains of $Y$. pestis. $Y$. pestis strains CO92 and KIM10 share $95 \%$ of their sequence with each other, but a comparison of the genome sequences reveals numerous re-arrangements [53]. It is also possible that the differences reflect differences in the experimental methodologies used to identify essential genes. The Himar transposon system used by Palace et al. [52] in their Tn-Seq studies preferentially targets TA motifs, whereas the Tn 5 system used in our study is more likely to insert into GC-rich sequences $[54,55]$. Additionally, different methodologies have been used to analyse the data. We have used an algorithm we have developed, which takes into account both the positions and frequencies of mutations in the target gene, as well as the phenomenon of background noise from sequencing. In contrast, Palace et al. used an HMM based method [52]. Finally, the bacteria were cultured in different ways after transposon mutagenesis. In our study Y. pestis CO92 was cultured in BAB-hemin whereas Palace et al. used TB with zeocin [52]. This raises the possibility that identification of essential genes might be dependent on the growth media and conditions $[56,57]$.

Many of the genes which were essential in both KIM1001 and CO92 have previously been identified as playing a role in central metabolism, and the finding that their disruption results in an effect on growth is therefore not surprising. For example, 46 of the genes encoded ribosomal proteins, 28 genes involved in carbon metabolism and 4. TCA cycle genes were identified as playing a role in the growth of both KIM10 and CO92. More interesting are those genes encoding proteins which are not found in humans, or where the human homologue is structurally diverse from the bacterial protein. These bacterial proteins might be exploited as drug targets. For example genes encoding proteins in the type II and Tat export pathways were identified as essential in both strains and the Tat system is currently being investigated as a target for small molecule inhibitors [58]. Five genes involved in lipopolysaccharide biosynthesis were identified as essential and may also be good drug targets. Other genes essential in both KIM1001 and $\mathrm{CO} 92$ which encode gene products unique to bacteria, such as the FtsZ cell division protein, the twin arginine transport (Tat) system and the SurA chaperone, encode potential drug targets. For example, currently there is significant interest in developing inhibitors of FtsZ [59]. Our study also identified novel targets for antimicrobial drugs including the hypothetical proteins YPO3498, YPO3579, YPO3586 and YPO3665/6/7 which encode the rod shape-determining proteins $\mathrm{MreB}, \mathrm{MreC}$ and $\mathrm{MreD}$ respectively. Collectively these findings highlight the potential to identify novel drug targets from essential genes.

Our data can also be used to identify mutations which result in reduced growth, and which could be exploited to generate live attenuated vaccines. Mutations in essential genes in both KIM1001 and CO92, including those encoding the catabolite repressor protein Crp [60,61], components of the translational quality control system $\mathrm{SmpB} / \mathrm{SsrA}$ [24], SpoT which is involved in the ppGpp synthesis [62] and Dam which is involved in DNA adenine methylation [63] have all been shown to be attenuated in mice and dosing with these mutants induces protective immunity.

\section{Computational analysis of a metabolic model of $Y$. pestis CO92 reveals environment-dependency of gene essentiality}

To explore potential dependency of gene essentiality on growth conditions, and to further verify our experimental gene essentiality list from a metabolic stance, we utilised a genome-scale metabolic network reconstruction of $Y$. pestis CO92 [17]. This model includes 815 metabolic genes, out of which 226 were identified as essential from our experimental study reported here. Using flux balance analysis (FBA) [18], we interrogated this model for metabolic reaction fluxes that can support pathogen growth in a given growth medium (see Methods). To mimic the growth of $Y$. pestis at different temperatures, we adapted the previous approach of using two different biomass objective functions (BOFs) that are designed to mimic 
the cellular requirements for replication under these conditions [17]. We conducted single-gene knockout analyses under each condition (see Methods), which resulted in the prediction of 149 and 146 metabolic genes as essential at $25{ }^{\circ} \mathrm{C}$ or $37{ }^{\circ} \mathrm{C}$, respectively. All of the genes predicted to be essential at $37{ }^{\circ} \mathrm{C}$ were also essential at $25{ }^{\circ} \mathrm{C}$, while there were three essential genes that were specific to $25{ }^{\circ} \mathrm{C}$ (YPO1139, YPO2063 and YPO3632). Given this overlap, we have conducted additional analyses described below only using the $25{ }^{\circ} \mathrm{C}$ BOF.

When we compared the 149 genes predicted by the model to be essential at $25{ }^{\circ} \mathrm{C}$ and the experimentally identified essential gene sets, we found that only 67 genes were common between them. As environment can influence the gene essentiality $[56,57]$, the discrepancy between the experimentally identified and the model predicted essential genes could be due to the use of different culture media for the transposon mutagenesis experiment (BAB broth medium) and in the metabolic model (BCS medium [17]). Since we do not know the exact chemical composition of the $\mathrm{BAB}$ broth medium, we have repeated the gene-essentiality analysis of the metabolic model using a large number of diverse media compositions. As a tractable starting point, we generated all possible combinations among the 17 BCS medium components, resulting in 131,072 media (see Methods). These media produced different essential gene set predictions. The media that produced the highest number of predicted essential genes also resulted in the highest overlap with the experimental data (Fig. 2a), and the number of essential genes decreased with the number of media components present (Fig. 2b). Using this data, we predicted an "essentiality score" for each gene, that is, the percentage of media where a given gene is found to be essential (Additional file 4: Fig. S1A). This revealed that some genes became essential only under media that was lacking specific media elements (Additional file 4: Fig. S1B). For example, a combined lack of glucose, glycine, and citrate revealed that a set of 8 genes became essential (Additional file 4: Fig. S1B). We then went on to perform a broader exploration of the space of possible media by generating over 2 million random media using the 281 exchange reactions in the model (see Methods). We found that several such randomly generated media produced a broader range of essential genes compared to the BCS medium and combinations thereof (Additional file 5: Figure S2). We combined both media sets and re-calculated the "essentiality score" for each gene. We found a set of 78 genes with an essentiality score of 100 (i.e. they were essential in all computationally tested media). Of these, $69.23 \%$ (i.e. 54 genes) were overlapping with
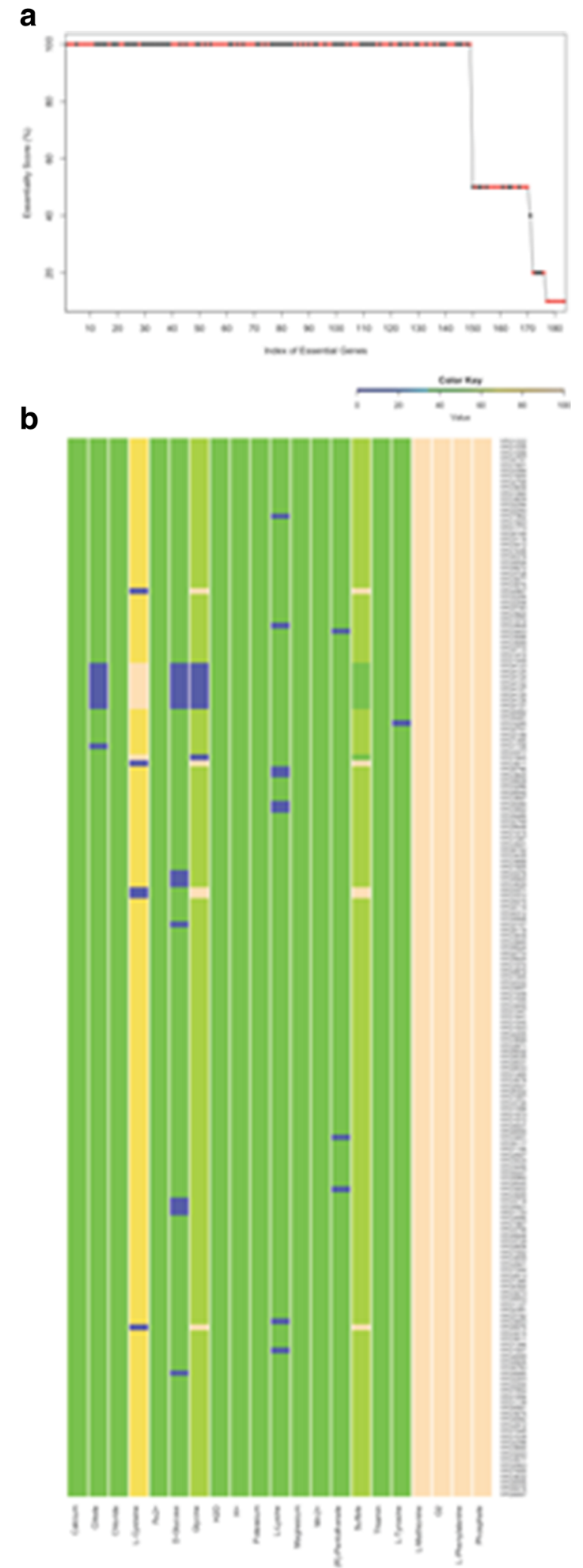
Fig. 2 The gene essentiality score and dependence of gene essentiality on specific media components found in BCS media. a Gene essentiality score based on media derived from BCS recipe. The $x$-axis lists all genes predicted as essential at least in one media, while the $y$-axis shows their essentiality score, calculated as the percentage of the media in which they are predicted to be essential. The overlap with experimentally identified genes in BAB broth media is marked in red. $\mathbf{b}$ A heat map showing media, in which a given gene was predicted to be essential, in terms of its components. The $y$-axis lists all genes predicted as essential at least in one media, while the $x$-axis shows media components. The colored boxes at each $x, y$ location indicate the fraction of media component ( $x$-axis) in all the media where that gene (y-axis) was essential. As shown in the color key, beige (blue) indicates all media, in which a gene was essential, containing (lacking) a specific media component

our experimentally identified essential genes under the BAB broth medium.

We have then identified a list of "core" essential genes by repeating the computational gene knockout analysis under a maximally-rich medium, implemented in the model by enabling uptake fluxes for all the exchange reactions (see Methods). This maximally-rich medium represents an environment with all the media components that $Y$. pestis has access to (according to the model). Therefore, the essential genes identified under this condition will theoretically be essential in all other media compositions. This analysis identified 78 "core" essential genes. These 78 genes are identical to the essential genes with an essentiality score of 100 identified in the above analysis, indicating that our randomly selected media provided a good coverage of the diversity of rich media.

\section{The core essential genes of $Y$. pestis $\mathrm{CO} 92$}

Taken together, our experimental results, their comparison with similar previous studies from other $Y$. pestis strains, and our computational analysis of a metabolic model under different environments, indicate a significant context dependency of gene essentiality. This is in line with the theoretical expectations $[56,57]$ and also fits the intuitive view that certain genes will only be required under certain environments. However, our analyses also highlight that a core set of genes are predicted to be essential in a broad range of environments and are also identified in our experiments and in other experimental studies.

In particular, we can conclude that the set of essential genes predicted both by the presented computational and experimental analyses (54 genes, Additional file 6: Table S4) correspond to genes that are particularly important for the growth of $Y$. pestis. The gene ontology (according to COG groupings) showed that the majority of these genes are related to transport and metabolism of various components, with coenzymes being the most numerous (Table 2). Of the genes we have identified, many are involved in the biosynthesis of fatty acids and lipids. The fabG (YPO1599), fabD (YPO1598), accA (YPO1060), $a c c B$ (YPO3659) $a c c C$ (YPO3658) and $a c c D$ (YPO2768) genes are located in the fatty acid biosynthesis pathway which has previously been identified as a target for antimicrobials [64, 65]. Although the reactions catalyzed by enzymes in this pathway are similar to those found in mammals, there are structural differences in the enzymes involved. This allows the targeting of the bacterial enzymes as for example in Isoniazid, which is used to treat tuberculosis, and triclosan, a broad spectrum antibacterial, both of which target the FabI step of fatty acid synthesis [65]. In lipid A biosynthesis, entire pathways (lpxA;YPO1056, lpxB:YPO1057, lpxD;YPO1054, $1 p x H$;YPO3075 and $l p x K$;YPO1396) were identified as essential, although some bacterial species are known to tolerate mutations in lipid A biosynthesis [66, 67].

\section{Re-assessment of reported gene essentiality data}

We have previously reported the experimental validation of selected essential genes [14] and here we interpret this data in the context of our findings here (Table 3). The first gene selected is $a c c A$, encoding acetyl-coA carboxylase, involved in biosynthesis of malonyl-coA, which is the precursor for fatty acid biosynthesis and already identified as a versatile antimicrobial target in many species [68]. This gene is also in the metabolic model and was identified as

Table 2 Gene ontology of core essential genes

\begin{tabular}{|c|c|c|}
\hline $\begin{array}{l}\text { COG } \\
\text { category }\end{array}$ & No of genes & COG function \\
\hline $\mathrm{F}$ & 5 & nucleotide transport and metabolism \\
\hline G & 3 & carbohydrate transport and metabolism \\
\hline $\mathrm{H}$ & 17 & coenzyme transport and metabolism \\
\hline I & 9 & lipid transport and metabolism \\
\hline M & 14 & cell wall/membrane/envelope biogenesis \\
\hline$P$ & 1 & inorganic ion transport and metabolism \\
\hline V & 1 & defence mechanisms \\
\hline $\mathrm{HI}$ & 1 & $\begin{array}{l}\text { coenzyme transport and metabolism, lipid } \\
\text { transport and metabolism }\end{array}$ \\
\hline GM & 1 & $\begin{array}{l}\text { carbohydrate transport and metabolism, cell } \\
\text { wall/membrane/envelope biogenesis }\end{array}$ \\
\hline IQ & 1 & $\begin{array}{l}\text { lipid transport and metabolism, secondary } \\
\text { metabolites biosynthesis, transport and } \\
\text { catabolism }\end{array}$ \\
\hline IQR & 1 & $\begin{array}{l}\text { lipid transport and metabolism, secondary } \\
\text { metabolites biosynthesis, transport and } \\
\text { catabolism, general function prediction only }\end{array}$ \\
\hline
\end{tabular}


Table 3 Experimental confirmation of essentiality

\begin{tabular}{|c|c|c|}
\hline Gene number & Gene name & Phenotype \\
\hline YPO1060 & $\operatorname{acc} A$ & Essential in broth and on agar \\
\hline YPO3293 & $\operatorname{trmD}$ & $\begin{array}{l}\text { Not essential in broth. Essential on } \\
\text { solid media. }\end{array}$ \\
\hline YPO2879 & $i s p G$ & $\begin{array}{l}\text { Not essential in broth. Essential on } \\
\text { solid media. }\end{array}$ \\
\hline YPO0038 & spot & $\begin{array}{l}\text { Not essential in broth. Essential on } \\
\text { solid media. }\end{array}$ \\
\hline
\end{tabular}

"super" essential, as described above. Two genes (isp $G$, spoT) were in the model, but identified as possibly non-essential under some environments, and one gene $(t r m D)$ is not contained in the metabolic model. Of these, the products of genes spoT and trmD are involved in the regulation of pppGp pools and tRNA production, and mutation of spoT has been shown to attenuate $Y$. pestis [62]. The gene product of isp $G$ is a diphosphate synthase found in the biosynthesis of isopentenyl diphosphate, which takes a junctional role in pathways leading to the production of longer chain carbohydrates, including terpenes, and mevalonate. For each gene, rhamnose-inducible/glucoserepressible mutants were made, and tested by growth in liquid culture or on solid medium (Table 3). This assay confirmed the essential nature of all the five genes for growth on agar plates, confirming the results of the TraDIS screen. The $a c c A$ mutant was unable to grow on agar or in broth, while the other three mutants were unable to grow on agar, but were able to grow in broth. These results confirm the conditional essential nature of isp $G$ and spoT, validating both the TraDIS screen and showing the usefulness of integration with the computational approach. Further physiological and infection studies are required to test the potential value of these and other identified genes as novel antibiotic targets.

In summary we performed and integrated experimental and computational study to identify essential genes in $Y$. pestis CO92. This approach identified genes that are differentially essential under $37{ }^{\circ} \mathrm{C}$ and $25{ }^{\circ} \mathrm{C}$, and under our experimental conditions. Our integrated approach highlighted environmentdependency of essential genes and predicted a small subset of genes that are core essential, in that their deletion is expected to impair growth under a broad range of conditions. As expected from this prediction, this core essential subset was mostly identified as essential in all experimental studies conducted on $Y$. pestis, including this study. These gene products are target for the development of novel disease interventions.

This integrated study also highlights the clear environmental dependency of essential genes. In the context of metabolism, this finding makes intuitive sense and shows the relevance of media components and cellular biomass composition for enzymatic requirements of the cell. Under different conditions, both media supplements and cellular composition are expected to change, rendering some of the metabolic pathways and enzymes obsolete or highly required. While our metabolic modelling approach can capture some of this variation in enzyme essentiality, it still does not provide a perfect match with experimental findings. A similar result of partial overlap was reported when comparing the essential genes predicted by metabolic modelling with essential genes identified using a whole genome mutagenesis approach in Neisseria meningitidis [46]. These discrepancies reflect that either the genome-scale metabolic models still miss key parts of metabolic pathways, or their assumptions on biomass composition are incomplete. The latter aspect could be explored in future studies by the computational exploration of different biomass composition constructions, while the former would be expected to improve with further physiological studies and genome annotations.

\section{Conclusion}

Using an integrated computational and experimental approach we have identified genes which are required for growth at $37{ }^{\circ} \mathrm{C}$ and under a broad range of environments. This work is important because we identify a number of candidate virulence factors in $Y$. pestis which have not previously been reported. These may be important targets for drug discovery or vaccine development. At a broader level our work is important because we demonstrate that the repertoire of essential genes identified using whole genome mutagenesis, now widely reported in a range of pathogens, is a fluid concept which is dependent on small changes in the environment.

\section{Additional files}

Additional file 1: Table S1. Sequences of adapters used during library preparation in this study. (DOCX $11 \mathrm{~kb}$ )

Additional file 2: Table S2. Primer sequences used during preparation of libraries for sequencing (DOCX $12 \mathrm{~kb}$ )

Additional file 3: Table S3. Essential genes identified in different strains of $Y$. pestis by different methods. Genes in KIM10 identified in in vitro expansion of a himar1-derived transposon library grown on TB agar containing $2.5 \mathrm{mM} \mathrm{CaCl}_{2}$ and $25 \mu \mathrm{g} / \mathrm{ml}$ zeocin at $37^{\circ} \mathrm{C}$, then analysed using the Hidden Markov model (50). Genes in CO92 identified after in vitro growth in $\mathrm{BAB}$ broth at both $28^{\circ} \mathrm{C}$ and $37^{\circ} \mathrm{C}$, then analysed using the DEM algorithm (14) (DOCX $48 \mathrm{~kb}$ )

Additional file 4: Figure S1. Analysis of gene essentiality using the genome-scale model and 2 million randomly generated media. A. Number of essential genes (blue bars; $y$-axis) predicted by the model using a specific random media composition derived from the available exchange reactions in the model ( $\mathrm{X}$-axis). The overlap with experimentally identified genes in BAB broth media is shown as well (red bars). $\mathbf{B}$. Number of essential genes (y-axis) predicted by the model using a specific media composition that is 
containing a given number of components of the available exchange reactions in the model (as shown in the $x$-axis). (TIFF $156 \mathrm{~kb}$ )

Additional file 5: Figure S2. Analysis of gene essentiality using the genome-scale model and 2 million randomly generated media (using available exchange reactions in the model). The $x$-axis list the number of genes identified as essential in a set of media (y-axis). (TIFF $95 \mathrm{~kb}$ )

Additional file 6: Table S4. Overlap between experimentally identified and computationally predicted essential genes. Lines 1-54 details genes that are predicted to be essential in all computationally tested media (100\% essentiality score) and are also experimentally identified to be an essential gene under the BAB broth medium. Lines 55-78 details genes that are predicted to be essential in all computationally tested media (100\% essentiality score) but not experimentally identified to be an essential gene under the BAB broth medium. The gene information was collected from http://www.genome.jp on October 18 2016. (DOCX 17 kb)

\section{Abbreviations}

BAB: Blood agar base; BOF: Biomass objective function; BCS; Bp: Base pairs; Cmk: Cytidine monophosphate kinase; COGs: Cluster of orthologous groups; DEG: Database of essential genes; dNTPs: Nucleoside triphosphates; FBA: Using flux balance analysis; HITS: High-throughput insertion tracking by deep sequencing; HMM: Hidden markov method; INSeq: Insertion sequencing; PCR: Polymerase chain reaction; TBE: tris-borate-EDTA; tmRNA: Transfer-messenger RNA; Tn-seq: Transposon sequencing; TraDIS: Transposon-directed insertion site sequencing

\section{Acknowledgements}

We thank the Exeter Sequencing Service for support with sequencing of the TraDIS libraries.

\section{Funding}

This work was funded by the Defence Science and Technology Laboratory, award DSTLX-1000060221 (WP1). The funding body played a role in the design of this study and interpretation of the data.

\section{Availability of data and materials}

The datasets supporting the conclusions of this article are available at the NCBI GEO website https://www.ncbi.nlm.nih.gov/geo/query/ acc.cgi?acc=GSE100226.

\section{Authors' contributions}

Conceptualisation OSS, RWT, MST, HSS, TPA; Formal analysis NJS, KS, RJS, AES, ZRY. Methodology NJS, KS, PMM, HLB, KM; Supervision OSS, RWT, TPA, HSS; Validation OSS, HLB, PMM; Visualisation KS, NJS, ZRY; Writing - review and editing NJS, KS, RJS, AES, MST, PMI, HLB, ZRY, KM, PCFO, TPA, HSA, OSS, RWT. All authors read and approved the final manuscript.

\section{Ethics approval and consent to participate}

Not applicable.

\section{Consent for publication}

Not applicable.

\section{Competing interests}

The authors declare that they have no competing interests.

\section{Publisher's Note}

Springer Nature remains neutral with regard to jurisdictional claims in published maps and institutional affiliations.

\section{Author details}

'College of Life and Environmental Sciences, University of Exeter, Exeter EX4 $4 S B$, UK. ${ }^{2}$ School of Life Sciences, University of Warwick, Coventry CV4 7AL, UK. ${ }^{3}$ Defence Science Technology Laboratory, Porton Down, Salisbury SP4 OJQ, UK. ${ }^{4}$ Marshall Centre for Infectious Disease Research and Training, School of Pathology and Laboratory Medicine, University of Western Australia, Perth, WA 6009, Australia.
Received: 26 April 2017 Accepted: 17 July 2017

Published online: 21 July 2017

\section{References}

1. Butler T. Plague history: Yersin's discovery of the causative bacterium in 1894 enabled, in the subsequent century, scientific progress in understanding the disease and the development of treatments and vaccines. Clin Microbiol Infect. 2014;20:202-9.

2. Vogler AJ, Keim P, Wagner DM. A review of methods for subtyping Yersinia pestis: from phenotypes to whole genome sequencing. Infect Genet Evol. 2016;37:21-36.

3. Galimand M, Carniel E, Courvalin P. Resistance of Yersinia pestis to antimicrobial agents. Antimicrob Agents Chemother. 2006;50:3233-6.

4. Inglesby TV, Dennis DT, Henderson DA, Bartlett JG, Ascher MS, Eitzen E, Fine AD, Friedlander AM, Hauer J, Koerner JF, et al. Plaque as a biological weapon: medical and public health management. Working Group on Civilian Biodefense. JAMA. 2000;283:2281-90.

5. Perry RD, Fetherston JD. Yersinia pestis - etiologic agent of plague. Clin Microbiol Rev. 1997;10:35-66.

6. Johnson TL, Hinnebusch BJ, Boegler KA, Graham CB, MacMillan K, Montenieri JA, Bearden SW, Gage KL, Eisen RJ. Yersinia murine toxin is not required for early-phase transmission of Yersinia pestis by Oropsylla montana (Siphonaptera: Ceratophyllidae) or Xenopsylla cheopis (Siphonaptera: Pulicidae). Microbiology. 2014;160:2517-25.

7. Cornelis GR. The Yersinia YSC-YOP 'type III' weaponry. Nature Rev Mol Cell Biol. 2002;3:742-52.

8. Chao MC, Abel S, Davis BM, Waldor MK. The design and analysis of transposon insertion sequencing experiments. Nat Rev Microbiol. 2016;14: 119-28.

9. Mobegi FM, van Hijum SA, Burghout P, Bootsma HJ, de Vries SP, van der Gaast-de Jongh CE, Simonetti E, Langereis JD, Hermans PW, de Jonge MI, et al. From microbial gene essentiality to novel antimicrobial drug targets. BMC Genomics. 2014;15:958.

10. Opperman T, et al. Microbial pathogen genomes - new strategies for identifying therapeutic and vaccine targets. Expert Opin Ther Targets. 2003;7:469-73.

11. van Opijnen T, Camilli A. Transposon insertion sequencing: a new tool for systems-level analysis of microorganisms. Nature Rev Microbiol. 2013;11:435-42

12. Basler G. Computational prediction of essential metabolic genes using constraint-based approaches. Methods Mol Biol. 2015;1279:183-204.

13. Rienksma RA, Suarez-Diez M, Spina L, Schaap PJ, Martins dos Santos VA. Systems-level modeling of mycobacterial metabolism for the identification of new (multi-)drug targets. Semin Immunol. 2014;26:610-22.

14. Yang ZR, Bullifent HL, Moore K, Paszkiewicz K, Saint RJ, Southern SJ, Champion OL, Senior NJ, Sarkar-Tyson M, Oyston PCF, et al. A noise trimming and positional significance of transposon insertion system to identify essential genes in Yersinia pestis. Sci Rep. 2016;7:41923.

15. Parkhill J, Wren BW, Thomson NR, Titball RW, Holden MTG, Prentice MB, Sebaihia M, James KD, Churcher C, Mungall KL, et al. Genome sequence of Yersinia pestis, the causative agent of plague. Nature. 2001;413:523-7.

16. Conchas RF, Carniel E. A highly efficient electroporation system for transformation of Yersinia. Gene. 1990:87:133-7.

17. Charusanti P, Chauhan S, McAteer K, Lerman JA, Hyduke DR, Motin VL, Ansong C, Adkins JN, Palsson BO. An experimentally-supported genomescale metabolic network reconstruction for Yersinia pestis CO92. BMC Sys Biol. 2011;5:163

18. Thiele I, Palsson BO. A protocol for generating a high-quality genome-scale metabolic reconstruction. Nature Prot. 2010:5:93-121.

19. Brubaker RR. Factors promoting acute and chronic diseases caused by yersiniae. Clin Microbiol Revs. 1991;4:309-24.

20. Seo J, Savitzky DC, Ford E, Darwin AJ. Global analysis of tolerance to secretin-induced stress in Yersinia enterocolitica suggests that the phageshock-protein system may be a remarkably self-contained stress response. Mol Microbiol. 2007;65:714-27.

21. Bossemeyer D, Borchard A, Dosch DC, Helmer GC, Epstein W, Booth IR, Bakker EP. K+-transport protein TrkA of Escherichia coli is a peripheral membrane protein that requires other trk gene products for attachment to the cytoplasmic membrane. J Biol Chem. 1989;264:16403-10. 
22. Su J, Gong H, Lai J, Main A, Lu S. The potassium transporter Trk and external potassium modulate Salmonella enterica protein secretion and virulence. Infect Immun. 2009;77:667-75.

23. Himeno $\mathrm{H}$, Kurita D. Muto A: tmRNA-mediated trans-translation as the major ribosome rescue system in a bacterial cell. Front Genet. 2014;5:66.

24. Okan NA, Mena P, Benach JL, Bliska JB, Karzai AW. The smpB-ssrA mutant of Yersinia pestis functions as a live attenuated vaccine to protect mice against pulmonary plague infection. Infect Immun. 2010;78:1284-93.

25. Taschner PE, Verest JG, Woldringh CL. Genetic and morphological characterization of $\mathrm{fts} B$ and $n r d B$ mutants of Escherichia coli. J Bacteriol. 1987;169:19-25

26. Sun J, Singh V, Lau A, Stokes R, Obregón-Henao A, Orme I, Wong D, Av-Gay Y, Hmama Z. Mycobacterium tuberculosis nucleoside diphosphate kinase inactivates small GTPases leading to evasion of innate immunity. PLoS Pathog. 2013;9:e1003499.

27. Yu H, Xiong J, Zhang R, Hu X, Qiu J, Zhang D, Xu X, Xin R, He X, Xie W, et al. $\mathrm{Ndk}$, a novel host-responsive regulator, negatively regulates bacterial virulence through quorum sensing in Pseudomonas aeruginosa. Sci Rep. 2016;6:28684.

28. Heithoff DM, Conner CP, Hanna PC, Julio SM, Hentschel U, Mahan MJ. Bacterial infection as assessed by in vivo gene expression. Proc Natl Acad Sci U S A. 1997:94:934-9.

29. Ginther $\mathrm{CL}$, Ingraham JL. Cold-sensitive mutant of Salmonella typhimurium defective in nucleosidediphosphokinase. J Bacteriol. 1974;118:1020-6.

30. Walker NJ, Clark EA, Ford DC, Bullifent HL, McAlister EV, Duffield ML, Acharya KR, Oyston PC. Structure and function of cytidine monophosphate kinase from Yersinia pseudotuberculosis, essential for virulence but not for survival. Open Biol. 2012;2:120142.

31. Fricke J, Neuhard J, Kelln RA, Pedersen S. The $\mathrm{cmk}$ gene encoding cytidine monophosphate kinase is located in the rpsA operon and is required for normal replication rate in Escherichia coli. J Bacteriol. 1995;177:517-23.

32. Beck CF, Neuhard J, Thomassen E, Ingraham JL, Kleker E. Salmonella typhimurium mutants defective in cytidine monophosphate kinase $(\mathrm{cmk})$. J Bacteriol. 1974;120:1370-9.

33. Chalker A, Lupas A, Ingraham K, So C, Lunsford R, Li T, Bryant A, Holmes D, Marra A, Pearson S, et al. Genetic characterization of gram-positive homologs of the XerCD site-specific recombinases. J Mol Microbiol Biotechnol. 2000;2:225-33.

34. Canavessi A, Harms J, de Leon GN, Splitter G. The role of integrase/ recombinase xerD and monofunctional biosynthesis peptidoglycan transglycosylase genes in the pathogenicity of Brucella abortus infections in vitro and in vivo. Microb Pathog. 2004;37:241-51.

35. Dillingham MS, Kowalczykowski SC. RecBCD enzyme and the repair of double-stranded DNA breaks. Microbiol Mol Biol Revs. 2008;72:642-71.

36. Wang G, Maier RJ. A RecB-like helicase in Helicobacter pylori is important for DNA repair and host colonization. Infect Immun. 2009;77:286-91.

37. Roche B, Aussel L, Ezraty B, Mandin P, Py B, Barras F. Iron/sulfur proteins biogenesis in prokaryotes: formation, regulation and diversity. Biochim Biophysica Acta. 1827:2013:455-69.

38. Tokumoto U, Takahashi Y. Genetic analysis of the isc operon in Escherichia coli involved in the biogenesis of cellular iron-sulfur proteins. J Biochem. 2001;130:63-71.

39. Connolly K, Rife JP, Culver G. Mechanistic insight into the ribosome biogenesis functions of the ancient protein KsgA. Mol Microbiol. 2008;70:1062-75.

40. Martinez-Gomez NC, Palmer LD, Vivas E, Roach PL, Downs DM. The rhodanese domain of Thil is both necessary and sufficient for synthesis of the thiazole moiety of thiamine in Salmonella enterica. J Bacteriol. 2011;193:4582-7.

41. Klein KA, Fukuto HS, Pelletier M, Romanov G, Grabenstein JP, Palmer LE, Ernst R, Bliska JB. A transposon site hybridization screen identifies gal $U$ and wecBC as important for survival of Yersinia pestis in murine macrophages. J Bacteriol. 2012;194:653-62.

42. Mecsas J, Bilis I, Falkow S. Identification of attenuated Yersinia pseudotuberculosis strains and characterization of an orogastric infection in $\mathrm{BALB} / \mathrm{C}$ mice on day 5 postinfection by signature-tagged mutagenesis. Infect Immun. 2001;69:2779-87.

43. Velayudhan J, Karlinsey J, Frawley E, Becker L, Nartea M, Fang F. Distinct roles of the Salmonella enterica serovar Typhimurium CyaY and YggX proteins in the biosynthesis and repair of iron-sulfur clusters. Infect Immun. 2014:82:1390-401.
44. Dahal N, Abdelhamed H, Lu J, Karsi A, Lawrence M. Tricarboxylic acid cycle and one-carbon metabolism pathways are important in Edwardsiella ictaluri virulence. PLoS One. 2013;8:e65973.

45. Jelsbak L, Hartman H, Schroll C, Rosenkrantz J, Lemire S, Wallrodt I, Thomsen L, Poolman M, Kilstrup M, Jensen $P$, et al. Identification of metabolic pathways essential for fitness of Salmonella Typhimurium in vivo. PLoS One. 2014;9:e101869.

46. Mendum TA, Newcombe J, Mannan AA, Kierzek AM, McFadden J. Interrogation of global mutagenesis data with a genome scale model of Neisseria meningitidis to assess gene fitness in vitro and in sera. Genome Biol. 2011:12:R127.

47. Vanaporn M, Sarkar-Tyson M, Kovacs-Simon A, Ireland PM, Pumirat P, Korbsrisate S, Titball RW, Butt A. Trehalase plays a role in macrophage colonization and virulence of Burkholderia pseudomallei in insect and mammalian hosts. Virulence. 2017;8:30-40.

48. Motin VL, Georgescu AM, Fitch JP, Gu PP, Nelson DO, Mabery SL, Garnham JB, Sokhansanj BA, Ott LL, Coleman MA, et al. Temporal global changes in gene expression during temperature transition in Yersinia pestis. J Bacteriol. 2004;186:6298-305.

49. Han Y, Zhou D, Pang X, Song Y, Zhang L, Bao J, Tong Z, Wang J, Guo Z, Zhai J, et al. Microarray analysis of temperature-induced transcriptome of Yersinia pestis. Microbiol Immunol. 2004;48:791-805.

50. Chauvaux S, Rosso ML, Frangeul L, Lacroix C, Labarre L, Schiavo A Marceau M, Dillies MA, Foulon J, Coppee JY, et al. Transcriptome analysis of Yersinia pestis in human plasma: an approach for discovering bacterial genes involved in septicaemic plague. Microbiology. 2007;153:3112-24.

51. Chromy BA, Choi MW, Murphy GA, Gonzales AD, Corzett CH, Chang BC, Fitch JP, McCutchen-Maloney SL. Proteomic characterization of Yersinia pestis virulence. J Bacteriol. 2005;187:8172-80.

52. Palace SG, Proulx MK, Lu S, Baker RE, Goguen JD. Genome-wide mutant fitness profiling identifies nutritional requirements for optimal growth of Yersinia pestis in deep tissue. MBio. 2014;5:e01385.

53. Deng W, Burland V, Plunkett G 3rd, Boutin A, Mayhew GF, Liss P, Perna NT, Rose DJ, Mau B, Zhou S, et al. Genome sequence of Yersinia pestis KIM. J Bacteriol. 2002:184:4601-11.

54. Lodge J, Weston-Hafer K, Berg D. Transposon Tn5 target specificity: preference for insertion at G/C pairs. Genetics. 1988;120:645-50.

55. Green B, Bouchier C, Fairhead C, Craig N, Cormack B. Insertion site preference of Mu, Tn5 and Tn7 transposons. Mob DNA. 2012;3:3.

56. Harrison R, Papp B, Pal C, Oliver SG, Delneri D. Plasticity of genetic interactions in metabolic networks of yeast. Proc Natl Acad Sci U S A. 2007;104:2307-12.

57. Barve A, Rodrigues JF, Wagner A. Superessential reactions in metabolic networks. Proc Natl Acad Sci U S A. 2012;109:E1121-30.

58. Vasil ML, Tomaras AP, Pritchard AE. Identification and evaluation of twinarginine translocase inhibitors. Antimicrob Agents Chemother. 2012;56: 6223-34.

59. Panda D, Bhattacharya D, Gao QH, Oza PM, Lin HY, Hawkins B, Hibbs DE, Groundwater PW. Identification of agents targeting FtsZ assembly. Future Med Chem. 2016;8:1111-32.

60. Sun W, Roland KL, Kuang X, Branger CG, Curtiss R 3rd. Yersinia pestis with regulated delayed attenuation as a vaccine candidate to induce protective immunity against plague. Infect Immun. 2010;78:1304-13.

61. Zhan L, Han Y, Yang L, Geng J, Li Y, Gao H, Guo Z, Fan W, Li G, Zhang L, et al. The cyclic AMP receptor protein, CRP, is required for both virulence and expression of the minimal CRP regulon in Yersinia pestis biovar microtus. Infect Immun. 2008:76:5028-37.

62. Sun W, Roland KL, Branger CG, Kuang X, Curtiss R 3rd. The role of relA and spoT in Yersinia pestis KIM5 pathogenicity. PLoS One. 2009;4:e6720.

63. Robinson VL, Oyston PC, Titball RW. A dam mutant of Yersinia pestis is attenuated and induces protection against plague. FEMS Microbiol Letts. 2005;252:251-6.

64. Parsons JB, Rock CO. Is bacterial fatty acid synthesis a valid target for antibacterial drug discovery? Curr Opin Microbiol. 2011;14:544-9.

65. Zhang YM, White SW, Rock CO. Inhibiting bacterial fatty acid synthesis. J Biol Chem. 2006;281:17541-4

66. Moffatt JH, Harper M, Harrison P, Hale JDF, Vinogradov E, Seemann T, Henry R, Crane B, St Michael F, Cox AD, et al. Colistin resistance in Acinetobacter baumannii is mediated by complete loss of lipopolysaccharide production. Antimicrob Agents Chemother. 2010;54:4971-7. 
67. Babinski KJ, Kanjilal SJ, Raetz CR. Accumulation of the lipid A precursor UDP2,3-diacylglucosamine in an Escherichia coli mutant lacking the IpxH gene. J Biol Chem. 2002;277:25947-56.

68. Freiberg C, Pohlmann J, Nell PG, Endermann R, Schuhmacher J, Newton B, Otteneder M, Lampe T, Habich D, Ziegelbauer K. Novel bacterial acetyl coenzyme A carboxylase inhibitors with antibiotic efficacy in vivo. Antimicrob Agents Chemother. 2006;50:2707-12.

Submit your next manuscript to BioMed Central and we will help you at every step:

- We accept pre-submission inquiries

- Our selector tool helps you to find the most relevant journal

- We provide round the clock customer support

- Convenient online submission

- Thorough peer review

- Inclusion in PubMed and all major indexing services

- Maximum visibility for your research

Submit your manuscript at www.biomedcentral.com/submit
Biomed Central 